\title{
How to make noncoherent problems more productive: Towards an AMR management plan for low resource livestock sectors
}

\author{
Andrea Butcher (iD ${ }^{1 凶}$, Jose A. Cañada ${ }^{2} \&$ Salla Sariola (iD $^{1}$
}

Global policy for managing antimicrobial resistance (AMR) is underpinned by a standardised and coherent global framework for reducing antibiotic use in clinical health, veterinary health, and food production sectors. Within the framework, problematic antibiotic use (a significant driver of AMR) is treated as a knowledge deficit on the part of users and prescribers, which can be remedied by educating them to make better informed treatment decisions. This narrow approach to AMR management conceals the socioeconomic and material drivers of antibiotic decision-making, creating challenges for low resource regions that rely on antibiotic therapies to manage uncertainty and precarity. Thus, there is a need for a global AMR policy that acknowledges the diversity of sociomaterial arrangements and practices that antibiotics form part of, if their use is to be reduced without undermining productivity or the attainment of poverty reduction indicators. Drawing upon research of antibiotic use in West Africa's livestock sector, this article analyses the interrelation of antibiotics, AMR action plans, and production management strategies in ecologies of livestock breeding practices. We apply the STS-influenced perspective of noncoherence to analyse how seemingly contradictory practices and institutional logics productively coalesce. We argue that observing noncoherent practices increases our understanding of antibiotic use in relation to local breeding conditions that are frequently not of the producers' making, whilst drawing attention to context-specific possibilities for improving livestock management capacities and reducing reliance on antibiotic therapies in low-resource settings. The article concludes by calling for an AMR global policy that is more responsive to local specificity rather than enforcing universal standardisation.

\footnotetext{
${ }^{1}$ University of Helsinki, Helsinki, Finland. ${ }^{2}$ University of Exeter, Exeter, UK. ${ }^{凶}$ email: andrea.butcher@helsinki.co.uk
} 


\section{Introduction}

n 2019 and 2020, we organised nine focus groups with West African veterinarians and livestock breeders to discuss their antibiotic practices and knowledge of antimicrobial resistance (AMR). We began each session by screening a short online film in which French industrial meat producers shared their techniques for managing animal health and reducing reliance on antibiotics. ${ }^{1}$ Their techniques were supported by sophisticated biosecurity innovations, such as improved housing and hygiene management, digital temperature control mechanisms, and 'smart' technologies to continuously monitor animal health. We used the video to engage participants with the theme of the focus group. However, when we asked if any of the issues presented chimed with their experiences, one Beninese veterinarian expressed bewilderment at our choice of footage. The advice given by French industrial famers had little relevance for the West African context, where breeders make do with limited space, struggle to manage hygiene, and lack the financial and technical means to implement robust biosecurity measures or install digital technologies. Why, he asked, had we not chosen a film more representative of local conditions? (The answer was we could not find one.)

In this article, we examine the challenges that breeders in Benin and Burkina Faso face adhering to global AMR governance as encapsulated in our opening vignette. AMR (the ability of microorganisms to acquire resistance genes to the drugs manufactured to control them) is considered a global challenge of such severity that experts fear it will result in tens of millions of people dying annually by 2050 from currently treatable infections, unless urgent action is taken to reduce reliance on antimicrobial therapies (O'Neill, 2016). These therapies include antibiotics, and in this article we focus specifically on attempts to curtail antibiotic use $(A B U)$. In low resource settings, where antibiotics can function as 'quick fixes' for managing infections, hygiene, uncertainty and poverty, reducing $\mathrm{ABU}$ is particularly challenging (Denyer Willis and Chandler, 2019). Our evidence demonstrates how, in West African breeding sectors, ABU supports positive production outcomes in situations where government extension and veterinary services are overstretched, diagnostic capacity is minimal, biosecurity is hindered by poor investment and technical capacity, and financial safety nets are lacking. Thus, the challenge is how to reduce reliance on antibiotics without causing additional or unintentional harms to livelihoods, food security and animal welfare in low-resource settings.

We argue that anticipating harms from reduction measures requires in-depth knowledge of the different roles antibiotics play in managing uncertainty across diverse settings, and that generating this knowledge requires fine-grained analysis of sitespecific socioeconomic, institutional and material complexities. Following Law et al. (2013) we conceptualise these roles as styles of noncoherence, which we use to analyse how heterogeneous and seemingly contradictory assemblages of materials, technologies, forms of labour, and institutional logics coalesce to make a service or policy framework operational. We explore the operation of noncoherences in ecologies of breeding practices (the broader organisational and professional arrangements that configure livestock management and breeding activities), demonstrating both the challenges and the opportunities they provide for implementing ABU reduction measures.

The article is structured as follows: we begin by summarising the global framework for managing AMR emergence and spread, and its implications for $\mathrm{ABU}$ in livestock management. We then lay out our noncoherence framework, which we apply to our analysis of antibiotic decision-making in production practice ecologies that may limit viable alternatives. After describing the West African breeding context, we explore the contingent practices and situations that drive decisions to use antibiotics, particularly where they support production outcomes (directly or indirectly). We conceptualise these situations as noncoherent problems. Finally, we discuss ways to make these practices and relationships noncoherent possibilities: productive sites of encounter that offer opportunities for designing more sustainable and equitable policy interventions that ensure the safe reduction of $\mathrm{ABU}$ in low-resource livestock sectors.

\section{Global AMR policy and its critics}

In 2015, the World Health Organisation developed its AMR Global Action Plan, or GAP in collaboration with the Food and Agriculture Organisation (FAO), and the World Organisation for Animal Health (commonly referred to as the OIE) (WHO, 2015). The GAP calls for an immediate and harmonised global response to reduce use in clinical health, veterinary, and food production sectors (WHO, 2015, p. vii), offering a standardised, coherent framework for goal alignment based on five objectives that all nations can work towards in individual national action plans. These objectives include improving public awareness of AMR and its mechanisms; surveillance and quantification of resistance prevalence; infection control; use optimisation; and investment in new treatments and diagnostics. The GAP's flexible arrangements for reporting and monitoring acknowledge the different capacities of member states for developing and implementing their plans (WHO, 2015, p. 6), and some international agencies provide technical and financial assistance to low-income countries who may need extra support achieving implementation (Gordon et al., 2020; Nwokike et al., 2018).

Livestock and fisheries sectors in LMICs are targets for AMR intervention for two reasons. Studies suggest that the global livestock sector is responsible for $70 \%$ of ABU (Van Boeckel et al., 2015, 2017); whilst low- to middle-income countries (LMICs) come under scrutiny due to high levels of poverty, inadequate healthcare facilities, poor sanitation and water treatment infrastructures, and weak regulatory and monitoring capacities (Collignon et al., 2018; Hendriksen et al., 2019; Singh, 2017). As a result, breeding sectors in low-resource regions (such as West Africa) are targets for external financial support and technical interventions to reduce $\mathrm{ABU}$ and improve infection control (AlMustapha et al., 2020; Alhaji et al., 2018; Iskandar et al., 2020; Singh, 2017; Van Boeckel et al., 2019). A particular stewardship challenge for global AMR policy is the ease with which livestock producers in LMICs can acquire antibiotics without prescription, either from registered vet pharmacies, farm supply shops, or via illegal drugs markets. Furthermore, policy-makers claim that poor farmer education and low literacy levels mean food producers have limited understanding of how antibiotic therapies function, and are thus unaware of the risks of misuse (Al-Mustapha et al., 2020; Alhaji et al., 2018; Iskandar et al., 2020). These studies assume that such 'knowledge deficit' can be remedied relatively simply by raising awareness of the dangers of indiscriminate $\mathrm{ABU}$, leading to an appropriate adjustment of behaviours (Tompson and Chandler, 2021).

Critical social scientists have highlighted the inadequacies of the 'knowledge deficit' model (Wynne, 2013) for understanding the socioeconomic, institutional and material contingencies that influence antibiotic practices and decision-making possibilities (Denyer Willis and Chandler, 2019; Hinchliffe et al., 2018; Kirchhelle et al., 2020). Studies have shown how, in both highand low-income countries, antibiotics are so thoroughly diffuse in clinical organisational cultures, individuals' expectations of care, and processes of food production that developing robust 
reduction strategies requires fine-grained analysis of the sociomaterial structures and practices they form part of (Broom et al., 2020; Chandler 2019; Waluszewski et al., 2021). In low-income countries, where antibiotics still play a critical role in povertyreduction measures, successful removal requires carefully planned interventions and investment in supportive infrastructures to replace them without undermining productivity or the attainment of poverty reduction indicators (Broom et al., 2020; Denyer Willis and Chandler, 2019; Kirchhelle et al., 2020; Tompson and Chandler, 2021). Kakkar et al., (2018) take up this issue for lowresource breeding sectors specifically, warning that reducing or removing antibiotics without understanding the drivers of $\mathrm{ABU}$ will undermine productivity. Furthermore, they argue that conventional management approaches developed in the global north are not suited to the less structured, more intricate and fragmented networks of actors and practices that characterise breeding sectors the Global South (Kakkar et al., 2018). Understanding the role antibiotics play in these breeder production ecologies is at the forefront of our analysis and recommendations for more flexible and responsive policy design.

\section{Theoretical framework}

We adopt an science and technology studies (STS) inspired perspective of noncohering practices (Law et al., 2013) to foreground the networked and multi-factorial nature of breeding sectors and professional environments today, which we use to build on Denyer Willis and Chandler's (2019) 'antibiotics as quick-fix infrastructure' reframing of the antibiotic overuse problem. In their persuasive critique, Denyer Willis and Chandler argue that antibiotics are now so integral to the functioning of contemporary societies, economies, and politics that they form part of the infrastructure we take for granted, claiming it is only now that antibiotics are failing that we notice their infrastructural character, along with the failing infrastructures they have been replacing. Understanding how antibiotics as infrastructure hold things in place in and across heterogenous settings, practices and institutional logics is key to understanding how they can be sustainably reduced or removed.

We find Law et al.'s (2013) concept of noncoherence particularly useful for analysing how these heterogenous logics and practices coalesce in ways that do not necessarily cohere, but are nonetheless productive (Butcher, 2017). Not to be misconstrued for incoherence, which can be interpreted as failure or incompatibility (Law et al., 2013, p. 174), noncoherence makes space for a variety of procedures, localised adaptations, and logics that coexist in operational terms. Through analysis of specific empirical examples, they identified six styles of noncoherence, which they labelled modes of syncretism: denial (of the diverse, messy labour required to make a programme of action work); domestication (smoothing differences into coherence); separation (the effort of keeping that which does not cohere apart); care (tinkering, experimenting, and negotiating with that which does not cohere); conflict (over how to organise that which does not cohere); and collapse (a blending of noncohering practices to provoke a result). These styles are not mutually exclusive, but rather they coalesce in syncretic ecologies (Law et al., 2013).

Noncoherence is useful for analysing how action plans and management practices operate. Using the AMR GAP as an example, we can argue that it strives for coherence by imposing a standardised framework for managing AMR that arguably privileges a 'view from everywhere' model, foregrounding harmonisation of global action over a 'baroque' vision for managing complexity, heterogeneity, and noncoherence (Haraway, 1988; Helmreich, 2009; Law, 2004). If we examine the AMR GAP as a noncoherent or syncretic ecology, we can propose that its determination for a harmonised response is a form of domestication. Each of the GAP's five implementation objectives require different kinds of expertise, labour, resources, and disciplinary logics; they are noncoherent, in other words. However, with this process of domestication (of grouping different objectives into a 'coherent' framework), the GAP denies the nature of its own noncoherence and its impact on implementation. It denies the extent to which antibiotics are infrastructural to the operation of particular sectors or institutional logics, turning denial into a conflict. This conflict is defined as failure (in the form of an implementation gap) rather than the consequence of domestication (which produces a façade of coherence). We could find more noncoherent styles in this example, and we will find new styles as we move through the analysis of our empirical examples. However, this short analysis outlines the premise of our argument: that by examining how antibiotics have become embedded in breeding practice ecologies, we can understand them in relation to other practices, economic dynamics, political and institutional arrangements, and so forth. This provides possibilities for designing innovative and more effective management solutions that can accommodate this complex network of actors, institutions, and practices.

\section{Methods}

This study formed part of an international multidisciplinary project consortium called antimicrobial resistance in West Africa (AMRIWA). ${ }^{2}$ The consortium is composed of medical and environmental microbiologists, molecular biologists and social scientists who follow the flow of antimicrobial resistance between people, nonhuman animals and environments. The evidence for this article is taken from the project's social science component. Given the sector's reliance on antibiotics, livestock breeding was a key site of sociological analysis. The research team consisted of social scientists and microbiologists from both Europe and West Africa. Data gathering took place across four fieldwork trips undertaken in 2019 and $2020,{ }^{3}$ applying primarily qualitative and ethnographic approaches. Our data pool included the nine focus groups with vets and breeders, along with interviews with seven breeders, three non-governmental training agencies, a veterinary scholar, three vet pharmacists, a ministry official, and three government para-veterinarians. We also interviewed a total of 12 ministry officials and local representatives of international organisations responsible for implementing the GAP. In addition, we observed three livestock agribusinesses ranging from 5-day visits, to a 3-week stay on a Beninese layer poultry farm. Interview data were either digitally voice recorded or hand-written, whilst field observations were hand-written and typed up each day (or, in more remote areas, when availability of electricity allowed). Interviews and focus group scripts were transcribed in French, translated using a digital translation service, and checked for accuracy. Documents were stored, coded, and analysed with the assistance of the qualitative data analysis platform Atlas.ti. Data were initially analysed inductively to identify emergent themes and practices relating to respondents' different experiences with antibiotics and AMR in West Africa's livestock sector, whether that be as producers, government advisors, or veterinary practitioners. From here, we began mapping out how the different organisational logics and practices existed in relation to each other to better understand how noncoherence operated in this particular ecology of production practices, finally settling upon three noncoherent styles: risk, production and implementation.

We encountered different kinds of participants in each country. For example, breeders participating in Beninese focus groups were predominantly young men running small-scale peri-urban farms with little to no formal training in livestock breeding. 
Many of these participants attended the focus groups to gather new knowledge and advice for improving their farming practices. By contrast, the Burkinabe participants were composed mainly of local businesspersons and entrepreneurs, operating larger agribusinesses with a higher level of professionalisation on the periphery of the capital Ouagadougou. These farms were often an adjunct business alongside their main enterprise, with respondents generally receiving training in livestock business management and marketing rather than technical knowhow, and hiring labourers to manage the animal rearing. This variance in participant backgrounds and farming systems was a result of partner networks rather than intentional sampling design. It allowed for comparison of their different perspectives and challenges, although we were less able to assess similarities and differences between the two national sectors as a result.

\section{The context}

In the history of modern livestock production, antibiotics have functioned to improve economic efficiency by preventing disease, promoting growth, and rationalising human labour (Kahn, 2016; Kirchhelle, 2018, 2020; Thoms, 2012). Antibiotics were routinely deployed on the newly industrialised farming systems of the western capitalist and eastern communist blocks during the mid20th century to prevent disease outbreaks in intensively stocked animals. However, boundaries between antibiotics' protective, therapeutic and economic deployment soon blurred as the rationalised economies of both East and West sought to improve efficiency across their intensive production systems. Soon, antibiotics were substituting labour as the method of 'caring' for livestock and managing hygiene, and being deployed as growth promotors to hasten the achievement of selling weights, or to increase available biomass for consumption (Kirchhelle, 2018, 2020; Thoms, 2012). LMICs' dependence on antibiotics grew from the 1970s onwards, when rising populations and corresponding demand for meat and eggs, along with technology transfer partnerships with foreign powers, precipitated the adoption of intensive farming practices (Kirchhelle, 2018). Concerns soon grew over the impacts of antibiotic residues and AMR for public health, and attempts to reform routine $\mathrm{ABU}$ in agriculture have globalised steadily if unevenly, with implementation dependent upon organisational structures and practice ecologies of the particular national sector (Waluszewski et al., 2021). Reform in both high and low-income regions remains a key policy focus for AMR control amid concerns for food safety, farm worker exposure, and environmental contamination from wastes such as manure or slurry (Hedman et al., 2020; Kirchhelle, 2018, 2020).

Following publication of the GAP in 2015, reforms have focused on reducing the use of medically important antibiotics in food animals, and in 2017 (following a review of farming in predominantly high-income countries) the WHO published guidelines for reducing $\mathrm{ABU}$ in livestock (WHO, 2017). The guidelines emphasise improving infection control, implementing robust farm biosecurity (sanitary barriers and housing or environmental conditions), establishing vaccination programmes, and the introduction of monitoring and stewardship programmes (WHO, 2017). They promote evidence-based prescribing and dispensing, whereby diseases are diagnosed by a veterinary professional preferably supported by a microbial culture and antibiotic sensitivity test. They further advocate the establishment of national surveillance programmes to evaluate implementation of these measures and track any emerging resistance in microorganisms (WHO, 2017). Even in high income countries, implementation of the guidelines can be hindered by the specificities of production practice systems, integrated supply chains, and just-in-time pressures (Buller et al., 2020; Hinchliffe, 2015; Waluszewski et al., 2021). For low-resource countries such as Benin and Burkina Faso, where operations are more fragmented and structures less well-organised, implementation challenges are more pronounced. Small-scale farming supports economic growth and food security, and is promoted as a livelihood strategy for thousands of small to medium scale producers (Belton et al., 2018; Kakkar et al., 2018). Monitoring high numbers of farms is more challenging, particularly if surveillance infrastructures are underdeveloped (Kakkar et al., 2018). Furthermore, these producers are less likely to possess the financial and technological capabilities required to establish biosecure, hygienic farms, with antibiotics serving as substitutes (Hedman et al., 2020).

Benin and Burkina Faso rank amongst the poorest countries globally (ranking 163 and 172 out of 190, respectively, according to Worldometer). ${ }^{4}$ Both countries are members of the West African Economic and Monetary Union (Union Économique et Monétaire Ouest-Africaine or UEMOA), a customs union of eight Francophone West African states. In theory, Union membership offers some degree of harmonisation of breeding regulations, including the importation, distribution and sale of veterinary medicines. Breeding in both countries has expanded in recent decades due to urbanisation and rising population numbers, and increasing the availability of affordable sources of protein is a key development deliverable for both national governments. ${ }^{5}$ As with much of the African continent, structural adjustment packages and economic liberalisation diminished public sector employment opportunities, and with few other livelihood choices available, many households and individuals have turned to animal rearing (Houedjofonon et al., 2020). Poultry sectors in particular have witnessed a proliferation in semi-professional backyard farms; aspiring breeders might receive a gift of three or four chickens from a friend or family member and then fabricate an enclosure in their compounds for minimal capital investment. In economies where household earnings are frequently irregular and unstable, livestock are a source of marginal income or quick cash: assets that can be liquidated with ease to pay for school fees or a family health emergency. Where this is the case, investing in farm improvements may limit potential returns to the household income (Hedman et al., 2020; Thompson, 2021). Furthermore, breeding enterprises support a range of formal and informal occupations, including the sale of veterinary supplies; the activities of development NGOs; and local businesses such as small supermarkets, charcuteries, restauranteurs, or petty market sellers.

Our study focused upon peri-urban, semi-modern agribusinesses and backyard farms, well serviced by private vet pharmacies. ${ }^{6}$ The majority of participants reared European, 'exotic' breeds of swine and poultry, specifically bred for faster growth or (in the case of poultry layers) improved egg production in modernised livestock production systems. The intensive nature of these systems required farmers to establish sanitary barriers and robust hygiene protocols, increase the use of chemical inputs, and purchase specially manufactured feeds to support the animals' growth and health. However, backyard farmers often lacked the technical or financial capacities to establish the recommended conditions. Furthermore, despite attempts at regulation and monitoring, backyard enterprises were less likely to be registered, and often in breach of legislation prohibiting livestock farming in urban areas. Officials appeared to turn a blind eye, possibly due to the importance of such ventures for income generation and food security, although some focus group participants hinted that ministry officials were among those ignoring legislation, having established their own urban farms as a side business.

Well-established entrepreneurs owned larger intensively managed farms, operated tighter protocols, and employed labourers of 
varying skill. The more professionalised farms we visited were examples of 'integrated' farming, combining intensive biosecure operations of poultry or swine (and sometimes rabbit) with freeroaming cattle for milk production or small ruminants for slaughter during religious festivals. Agricultural products cultivated included cereals (e.g. maize or cassava), fruits (e.g. papaya and mango), and palm for its oil. Swine breeders reared pigs for both slaughter and husbandry, selling sows and boars to other farms, or exchanging males between one another to maintain genetic diversity. Water was supplied by boreholes drilled onsite, and farm wastes such as chicken manure or pig slurry were either recycled for agricultural use, or else removed by vacuum tankers. Despite greater professionalisation and the appearance of better financial security, these enterprises still operated with high levels of financial and disease exposure risks, with no financial protection or insurance mechanisms should they experience catastrophic disease and mortality.

For example, UEMOA regulations meant veterinary supplies were sourced from approved European or Asian import distributers, leaving vets and breeders vulnerable to variations in foreign currency exchange rates over which they had little control. Furthermore, local feed manufacturers could charge high prices for good quality feeds, which could be a business' heaviest production cost (of higher value than human resources). Despite high production costs, the significant number of producers and low consumer purchasing power kept selling prices low. Breeders and other industry specialists frequently mentioned how prone their animals were to disease, which they attributed to immune systems poorly adapted to the hot and humid climes, or compromised by selective breeding. ${ }^{7}$ The poultry hatchery sectors in both countries were underdeveloped, thus many businesses sourced their chicks from neighbouring countries, or as far afield as Belgium, resulting in immunities weakened by the stress of travel. 'Local' chickens were valued for their superior flavour and disease resistance, and some smallholdings or artisanal businesses bred them for consumers willing to pay a higher price for their meat. However, the 45-day production cycles and quick returns from fast growing broilers made this production system financially more viable, despite the elevated production risks. Egg production was achieved with European layers. Business risks were mitigated to an extent by agriculture, free-range animals, or other non-farming enterprises (for example, some entrepreneur respondents also owned construction businesses or electronic sales firms). Nevertheless, poor financial protection was a driver of risky decision-making and a potential AMR pathway as we shall see below.

Respondents of both countries were recruited from areas located in or around the urban centres, had relatively good access to telecommunications and veterinary supplies, and were generally educated to at least secondary level (whether hired technicians or farm owners). As a result, knowledge of antibiotic therapies, their function, and the risks posed by their misuse were well known, as was the importance of hygiene and biosecurity for managing disease. None of our respondents discussed using antibiotics to promote animal growth, nor did we find any evidence of this practice during farm stays (although as the above conversation demonstrated, the boundaries between treatment, prevention and economic output in livestock sectors can easily become blurred). However, many of our respondents lacked formal breeding training and whilst having some awareness of AMR, few were aware of global or national antibiotic regulations and recommendations. Furthermore, additional pressures and peripheral associations beyond the site of the farm (both human and non-human) disproportionately affected breeding conditions in unpredictable ways, able to influence and intensify financial or disease risk landscapes. In both countries, veterinary antibiotics were easily available without prescription. As a result, antibiotics still formed a significant, if not exactly routine, part of the production practices, driven by contingencies relating to disease and hygiene management in situations of infrastructural lack, which we analyse now as 'noncoherent' problems.

\section{Noncoherent problems}

Noncoherent problems occur for global policy when heterogeneous practices and institutionalised logics coalesce, provoking a challenge to the principle of coherent and harmonised global response to AMR management. We advance three overlapping noncoherent problems in our analysis: implementation, risk, and production. We define implementation noncoherences as situations where the objectives of AMR action plans compete with other development programmes or social challenges, for example responses to poverty reduction or improving food security. We can find risk noncoherences at sites where different strategies for influencing desired outcomes come together in uneasy tension. As with implementation noncoherences, risk noncoherences occur when policy objectives conflict with other imperatives, for example when AMR recommendations conflict with financial risk management in economically vulnerable settings, or when strategies for infection control and biosecurity contradict each other, potentially resulting in unintended and undesired outcomes. Like Law et al.'s (2013) care syncretism, actors tinker and experiment with available resources and possibilities, searching for a fix to an urgent problem. We define production noncoherences as situations whereby animal management practices developed for global northern breeding systems encounter localised systems and contexts, for example raising animals selectively bred for production and profit maximisation in hyper-intensive agribusiness systems on backyard farms or smallholdings in low-resource periurban areas. The farmers still manage to produce, despite the absence of viable infrastructures to support biosecurity adaptations; however, it creates new vulnerabilities and risks to be managed. As should already be clear, these noncoherence styles are entangled rather than distinct categories, overlapping and interacting in noncoherent ecologies. Below we examine how these noncoherences operate in relation to specific aspects of farm management, as well as to each other.

Implementation noncoherence: accessing professional support. Both Benin and Burkina Faso have ministry directorates and extension services for managing agricultural food production, guaranteeing food safety, and providing training opportunities for breeders. Extension services are responsible for providing breeders with information on emerging diseases and problems related to antibiotic resistance. In theory, both sectors offer financial assistance to breeders to establish their businesses in a biosecure manner, which they can apply for from agricultural development funds. Registering one's farm with ministry agencies provides both legal recognition and technical support. However, neither ministry had sufficient funds or the quantity of trained specialists required to service the high number of smallholdings and medium-sized farms. In Benin, breeders were theoretically obliged to register their farms for a modest one-time fee of 10,000 CFA ( €15). However, focus group respondents described being disincentivised by heavy interest rates on loan repayments, obligations to use state-approved 'expensive' veterinary services, and additional 'taxes' being demanded by some officials. Some reported submitting applications but receiving no acknowledgement or response. Others claimed to be unaware of the need to register. In Burkina Faso, according to ministry agents, there were simply too many farms to register and too few expert staff to monitor them. As a result, many businesses fell outside ministry 
monitoring structures. This meant agencies were unable to achieve the GAP's first objective of raising awareness of AMR and the role of antibiotic therapies in its evolution and acceleration.

Instead, private sector organisations provided training in business management and husbandry for a fee, developing their procedures in line with HACCP management standards (Hazard Analysis Critical Control Point, the global standard for managing food safety-related risk). In addition, many of our respondents claimed they were self-trained either using internet searches, by relying on networks of family and friends, or by joining one of plentiful WhatsApp or Facebook groups set up to share farm management information and training opportunities, and to request diagnostic advice by sharing photographs of afflicted animals or faecal matter. The ubiquity of wireless digital infrastructures and mobile telephony services plugged the gaps left by underfunded ministries and substandard diagnostic capacities of low-resource settings, facilitating the creation of vernacular networks offering professional support. We thus define this situation as an implementation noncoherence, whereby conventional infrastructures for effective communication, education and knowledge sharing (as identified by the WHO's, 2015 GAP) are weak and inefficient, but alternative (and possibly overlooked) communication routes exist (see also FAO, 2020).

Both countries also lacked laboratory capacities in terms of facilities, technologies, and trained experts. At the time of writing, Benin had two reference laboratories for veterinary research, whilst Burkina Faso had one. As a result neither country was able to implement national surveillance programmes for providing information on the incidence and prevalence of AMR genes or newly emerging resistant microorganisms in their locations as required by both the GAP and the WHO's guidelines for ABU in food producing animals (2017). The lack of laboratory capacity also influenced risk noncoherences in breeding management practices, which we turn to now.

Risk noncoherence: diagnostic dilemmas. As stated above, Benin and Burkina Faso faced challenges when adhering to the evidence-based diagnostic and prescribing framework laid out in the WHO's (2017) guidelines for ABU in food producing animals. Poor access to laboratory analysis was one factor, with veterinary and breeder respondents complaining that antibiograms (antibiotic sensitivity tests) were costly not only in financial terms, but also in the time it took to receive results, and few breeders were willing to risk waiting to treat their animals (particularly if there was a chance of losing one's $200 \mathrm{~kg}$ bull, as one Burkinabe vet phrased it). Another factor was a reluctance to call upon veterinary assistance, with breeders relying on their own knowledge and observation when diagnosing infections and disease outbreaks. Basic knowledge of disease was considered necessary if breeders were to react in a timely manner to a potentially morbid situation, with diagnostics forming part of both public and private training programmes. In general, veterinary assistance was requested only after breeders' own care practices had failed and they were facing mass mortality (a point on which vets concurred with much consternation).

There were valid reasons for breeders' reluctance to rely on professional veterinary support. We could refer to the obvious avoidance of callout fees which, whilst seemingly modest $(2000$ fcfa [€3] per visit or a small monthly fee of around €20), could stress already tight business margins. However, breeders also framed their reluctance in terms of biosecurity: vets posed a contamination risk, particularly if they had visited multiple farms beforehand. Ministry protocols for both countries dictated that vets restrict themselves to a maximum of two farm visits per day to avoid any cross-contamination of pathogen infection.
However, following protocol was financially unfeasible for some vets, who argued they had no choice but to attend multiple callouts to make a viable living. For breeders, this was interpreted as vets motivated by money taking unnecessary risks with their animals, particularly if they did not adhere to hygiene protocols (e.g. changing sanitary gowns or gloves). Here, global guidelines for diagnostic best practice conflicted with regional biosecurity protocols, producing a risk noncoherence.

As our analysis progressed, we began noticing more noncoherent risk management strategies coming together. Other veterinary respondents stated that they themselves declined to visit multiple farms. Reasons included time pressures, or petrol costs that exceeded the callout fee (particularly if the farm was located some distance away). Instead, both breeders and vets reported conducting consultations using mobile phones for a nominal fee (if payment was received at all). Some vets stated it was possible to do diagnostics without physically visiting the farm, which breeders preferred as it allowed them to make what could be lifesaving (and thus business-saving) decisions. In another example, one vet explained how he refused to enter farms during a suspected outbreak of a viral disease, recognising the contamination risk he posed. He was subsequently criticised by his customers for neglecting their animals. Strategies for limiting daily farm visits could be as risky as visiting too many farms, particularly if the farm suffered mortality as a result.

In these examples, we again noticed how breeders and vets displayed innovation as they tinkered with such diagnostic dilemmas to find short-term workable solutions, weighing up the risks of the distinctive disease management strategies against each other. Calling on veterinary expertise posed an infection risk (and by extension an ABU and AMR risk, although breeders did not frame it in those terms); whilst a lack of veterinary expertise (either due to the high number of farms, to manage overheads, or to prevent cross-contamination) increased the risk of unauthorised $\mathrm{ABU}$ if breeders were given no option but to make their own treatment decisions in the absence of a consultation. These examples demonstrated the challenges for implementing global diagnostic guidelines that conflicted with local breeding conditions, creating production vulnerabilities that businesses needed to manage.

Production noncoherence: vulnerabilities. Even when displaying good knowledge of appropriate husbandry and hygiene management, farms still operated with tight business margins and high levels of financial risk, struggling to bear the brunt if disease outbreaks occurred for reasons beyond their control. For example, breeder respondents on a large poultry layer farm in southern Benin reported once losing an entire cohort of chicks to disease after their international supplier neglected to vaccinate them properly. With no insurance or compensation provision, and with business margins further stretched by increasingly unfavourable market dynamics, the owner had struggled to recover financially. This was a well-managed farm of some 20,000 layers. Production was good and disease outbreaks were generally low, which the owner proudly attributed to strict adherence to good hygiene and biosecurity measures, an optimal feeding regime with a highquality product, and a cohort of well-trained staff. Nevertheless, the owner acknowledged that finances prevented him from adapting farm biosecurity measures further. He regretted that there were no handwashing or shower facilities at the gate. ${ }^{8}$ 'Protective' clothing was restricted to footwear only: slip-on rubber sandals that both staff and visitors (anyone crossing the sanitary barrier in other words) were required to wear. The sandals functioned to prevent contamination beyond the barrier rather than providing any protection to the feet of those wearing them. 
The farm labourers worked in them daily, up to their ankles in chicken manure unless they found the money to buy themselves proper protective boots. As financial margins tightened, so too did money for recommended hygiene inputs such as disinfectants. Staff were therefore disinfecting their sandals in filthy footbaths, only able to change the solutions every two to three days. The technicians expressed concern for their own health due to poor levels of protection. We analyse these challenges as production noncoherences, whereby the need for cheap and plentiful protein has driven greater intensification of farm management without supporting investment in financial safety nets or infrastructural adaptation, thus creating new production vulnerabilities for breeders to manage.

Here, questions of hygiene and biosecurity (or the lack thereof) were pertinent not only for the health of the animals but also for the safety of hired labour. Across the semi-modernised agribusinesses observed, wages were low, and the accommodation basic. Latrines and bathing areas were communal and poorly maintained. The work could be physically demanding, with long hours and few days off. Labourers' nutritional needs were not adequately met (some quipped that the animals in their care ate better than they did), and many complained of fatigue and no time to clean their work clothes, washing them once a week (rather than following each use as protocol dictates). Taking time off meant losing wages, and staff said they continued to work even when sick with malaria or typhoid (although these conditions tended to be self-diagnosed, with low wages limiting access to formal healthcare). Many claimed never to use antibiotics, choosing to rely instead on traditional remedies purchased at local markets or gathered from plants around the farm. In practice however we observed some reliance on chemical therapies. For example, one Beninese labourer admitted to taking poultry antiparasite medicines to prevent contamination from the intestinal parasites that the hens were permanently infected with. On another occasion a Burkinabe labourer experiencing gastrointestinal problems, and unable to afford the fees for primary healthcare, had purchased a Trimethoprim antibiotic from a nearby village kiosk, supplied via a smuggling route out of Nigeria.

The problems labourers faced cannot be attributed solely to difficult business margins; lower social status also governed their treatment. Nevertheless, economic margins influenced the range of decision-making possibilities, creating further risk noncoherences as owners tinkered with decisions over whose health to privilege, despite the continued risk of cross-contamination due to neglect of staff welfare and proper hygiene management. Thus, even when $\mathrm{ABU}$ was well controlled, poor wages, inadequate and unsanitary living conditions, and suboptimal protective clothing undermined the effectiveness of sanitary barriers, potentially requiring antibiotics to pick up the slack. Furthermore, unable to access proper healthcare, technicians and labourers relied on informal markets where drug quality is not guaranteed and dosages cannot be monitored. In West African breeding ecologies, the vulnerabilities created by production noncoherences were borne by the labourers, but the risk was distributed across the farm.

Noncoherent ecologies: perils of withdrawal. As well as contributing to the food security of their respective populations, Benin's and Burkina Faso's breeding sectors supported the livelihoods of other businesses and individuals ranging from local supermarket franchises, to restaurants and low-end eateries, to petty market sellers. Under HACCP food safety rules, to prevent customer contamination with antibiotic residues in food, producers must observe the required withdrawal periods (the minimum period between administration of final antibiotic dose and onward sale). In the West African context, should a farm pause it sales due to disease outbreaks, the absence of financial safety nets could result in substantial-even catastrophic-loss of earnings not only for the farm, but for any business that relied on the farm's produce for its survival.

Returning to the Beninese layer farm, the business produced $\sim 12,000$ eggs per day from its 20,000 hens, which were sold in trays of 30 eggs for either $1500 \mathrm{cfa}$ or $1800 \mathrm{cfa}$ per tray (depending on the size of the eggs). Four hundred trays at 1800cfa per tray is $\sim 1000$ per day. The research team was permitted access to the poultry management records: hand-written ledgers logging details of medicinal treatments, disease events, and cases of mortality. According to these ledgers, disease outbreaks were infrequent and deaths were few. However, during the first 6 months of 2019, outbreaks of bacterial infections had occurred almost monthly. If a bacterial infection was suspected, the official line was to separate the infected birds from the main enclosures, isolate them whilst they were treated with antibiotics, and return them to the flock once treatment and withdrawal were complete ( 5 and 7 days, respectively). However, on consulting the ledgers it became clear that farm management took a metaphylactic approach: if a bacterial infection was suspected, technicians treated the entire flock to prevent its spread. Reasons for this related to the method for diagnosing infections in intensively managed conditions. Poultry bacterial diseases (for example salmonella or infectious bronchitis) were diagnosed through observation of faecal matter in the litter (nutrient-rich bedding made from organic materials enriched by the poultry manure). ${ }^{9}$ Given that poultry litter was the habitat for the entire flock, all birds would be exposed, elevating the risk of mortality and major business losses-hence the metaphylactic approach. Observing withdrawal periods would mean 12 days unable to sell eggs, resulting in a loss of 144,000 eggs and $\sim 13,000$. If the farm stood to lose almost half its income each month, the business would collapse. Conversely, not assuming systemic infection and isolating only the birds showing symptoms was risky if all birds were exposed and potentially infected. In either scenario, not only would the owner and labourers risk losing their livelihoods, but supermarkets, restauranteurs, and the market sellers-anyone relying on the eggs for their own incomes-would also suffer losses, not to mention the loss of food supply for the local population. Thus, even with relatively well-managed farms, antibiotic decision-making was shaped by the absence of financial protection and compensation, and the capacity to manage AMR risk was determined by the immediacy of business collapse and loss of food supply-a further risk noncoherence. As a production noncoherence, this situation compels us to consider the kinds of institutional and technical support required to ensure observation of withdrawal periods does not create new vulnerabilities in low-resource settings, and by extension how those infrastructures can improve outcomes at sites of implementation noncoherence, in this case how to adhere to AMR policy recommendations without risking livelihoods and food supply.

\section{Noncoherent possibilities}

Our analysis of the West African breeding practice ecologies in which antibiotics are entangled has foregrounded the vulnerabilities created when attempts to modernise meat production occur without supporting investment in infrastructures and diagnostic technologies, improved access to veterinary support, or investing in expert training. We conceptualised our examples as a coming or bringing together of noncoherent problems, looking for practices, relationships and connections in empirical examples that global institutions responsible for drafting the GAP had not 
predicted or anticipated. With risk noncoherences, we found calling on veterinary assistance was not simply a matter of good farmer behaviour and a stock of available and willing vets, but rather a series of negotiations and trade-offs relating to tight margins, time pressures, and the ability of both parties to manage hygiene. Onsite veterinary consultation posed a contamination risk, thus adhering to global recommendations for doing diagnostics risked the possibility of spreading drug-resistant pathogens between farms. Production noncoherences were shaped by vulnerabilities produced by entrenched inequalities between employer and labourer, or between global pharmaceutical markets and local economies. Financial risk management strategies, driven by financial shock absorbers, influenced managerial decisions that included whose health to prioritise, even as those decisions meant compromising on biosecurity measures and leaving the farm susceptible to infection transmission. Decisions to waiver food safety standards (such as observing withdrawal periods) became implementation, risk, and production noncoherences once livelihoods and food security were on the line, raising the question once again of how to adjust practices to reduce reliance on antibiotics without risking animal welfare, livelihoods and food supply.

However, identifying these the problems encouraged us to think about the noncoherent possibilities for developing alternative methods for implementing the GAP objectives that are more responsive to specific national or regional contexts. Exploiting noncoherent possibilities requires a nuanced appreciation of how the different forms of labour, expertise, existing technologies and material conditions come together to make a farm productive. The examples of noncoherent possibilities we provide rely more on locally available resources and may support the GAP framework to positively respond to some of the challenges presented above. Our first possibility addresses the challenge of veterinary oversight and information sharing by investing in digital methods of veterinary consultation or extension services to support the objective of improving awareness and understanding of AMR. Current diagnostic protocols are better adapted to high income regions, where it is possible for fewer vets to support the smaller numbers of intensive or hyper-intensive farms (where the concentration of animals is greater, and where digital tools are on hand to assist the diagnostic process). This proves more challenging for low-income regions where food is produced by hundreds of smallholdings or mid-range farms, with limited veterinary support and few laboratory resources. Instead, digital communications technologies provide opportunities for developing or strengthening digital extension services or mobile veterinary consultations in situations where access to diagnostics or the ability to visit farm are limited (Suchiradipta and Saravanan, 2016), at least for the literate and digital-savvy breeders in peri-urban areas. Whilst this is an imperfect system, it may help farmers to make more informed decisions about when not to use antibiotics, for example if the possibility of a bacterial infection can be confidently ruled out. Social media tools can be used to raise awareness of AMR and how to manage it, thus fulfilling the GAP's first objective. As a noncoherent possibility, it is far easier to adjust the framework to fit the practices of the hundreds of small-to-medium scale farms in the region, rather than obliging them to cohere with the current framework.

Our second possibility addresses the shortage of surveillance technologies and technical capacities through the development of alternative indicators and techniques, and the design of low-cost vernacular solutions for managing biosecurity and reducing incidences of infection. We found that local research centres and private organisations in both countries experimented with traditional local remedies to find compounds that could be applied as alternatives to antibiotics, or to the chemical disinfectants for managing farm hygiene. In Burkina Faso, the breeding specialist organisation Faso Elevage Sarl recommended using traditional remedies for managing health and farm hygiene, particularly in areas less well serviced by vet supply shops. The Songhai Centre in Benin (a nongovernmental sustainable development organisation) ran experiments with effective micro-organism technologies for improving livestock gut microbiota and managing farm hygiene. Similarly URMAPha, ${ }^{10}$ a Beninese research unit (and AMRIWA project partner), analyses the antibacterial properties of local pharmacopeia, searching for plants with the potential to act as alternative treatments to manufactured antibiotic therapies. Further observation of regional farm management uncovered practices that can be exploited for their disease control potential. For example, on a Burkinabe pig farm, the owner supplemented his feed with waste yeasts purchased from a local brewery to reduce his production expenditure. However, studies indicate that brewers' spent grain may be beneficial for improving animal gut microbiota and inhibiting pathogen emergence (Bianco et al., 2020), suggesting that as well as a method of reducing feed costs, this practice could also be improving animal immunity. Investment could be directed towards establishing collaborative partnerships between social scientists, local research centres and food producers to identify similar practices and design experiments to test their viability as low-cost vernacular solutions for improving immunities, preventing disease, and reducing reliance on antibiotics.

In situations where the establishment of robust surveillance databases is unlikely to be achieved in the short to medium term, funding and investment can be directed towards designing experiments that utilise local knowledge and experience for developing locally appropriate technologies to manage biosecurity and disease control, or to develop alternative surveillance techniques and health monitoring systems based on careful observation of farm dynamics and identification of disease stressors. In so doing, the GAP objectives for establishing surveillance techniques and improving infection control will be fulfilled. Adapting the framework's ability to accommodate the local realities for breeding sectors is a more workable strategy than threatening the viability of breeders' livelihoods by obliging them to cohere with current guidelines.

\section{Concluding words}

Many of the challenges for reducing $\mathrm{ABU}$ in livestock are structural in character, and require medium to long-term investment in both time and resources (Tompson and Chandler, 2021), for example building laboratory capacities, establishing compensation schemes to protect against business losses, and building the capacities of national ministries to adequately support their sectors. Similar investment is required to improve supportive infrastructures that we have not discussed in this article, such as establishing robust vaccination programmes or improving sanitation, wastewater and water supply infrastructures. However, our analysis of current conditions for breeders in West Africa has highlighted the specific and noncoherent practices, institutional apparatuses, and information flows that can provide the foundations for supportive professional environments geared towards reducing reliance on antibiotics. Just as practices and relationships with antibiotics change between sectors, nations and regions, so too do farming and production strategies, diagnostic protocols, best practice guidelines, and opportunities for action and intervention. Just as making a farm work is a case of stitching together that which does not cohere (Hinchliffe, 2015), operationalising the GAP requires stitching together noncohering assets, expertise and forms of labour to adapt the guidelines to local conditions and available 
resources for managing health and hygiene. Our novel approach for addressing $\mathrm{ABU}$ provides such a framework by foregrounding the networks and ecologies of practice within which antibiotics and their use practices are embedded, and which finds within them the potential to design interventions that act directly or indirectly on use reduction.

Accepting heterogeneity in a programme for change requires dismantling well-entrenched governance and policy arrangements that are determined by standardisation and harmonisation of action, and we recognise that this is a major challenge. It requires asking whether all countries should follow the same path to reduce $\mathrm{ABU}$. It requires asking what alternative and productive information routes, animal health management techniques, or biosecurity strategies exist on the ground that can be made operational. It requires asking what sites and spaces can be intervened in, and what kinds of experiments are required to make those interventions viable. Ultimately, it requires those responsible for developing global health guidelines to recognise that, rather than a knowledge deficit or an unwillingness to adapt, implementation failures can be a consequence of processes of domestication, and the denial that sustainably reducing reliance on antibiotics requires different kinds of noncohering resources, labour, and assets. There are signs that this kind of thinking is gaining ground at the macro-level. Global agencies are beginning to recognise the significance of context as a driver of $A B U$ and AMR emergence, and the importance of adaptive change across multiple sites and organisational boundaries to find sustainable and dependable management solutions (Ledingham et al., 2019; World Bank, 2019), whilst Kenya's national action plan has institutionalised a citizen-generated approach for producing AMR surveillance data (GPSDD, 2021). With a willingness to let go of uniformity and make room for contingency and heterogeneity, it is possible to harness noncoherent practices to find what works and to identify practices that can be used to design alternative antibiotic management infrastructures, rather than obliging diverse national governments and professional sectors to adopt standardised management strategies that offer little flexibility, and that can potentially cause new harms.

\section{Data availability}

The datasets generated and analysed during the current study are not publicly available due to ethical considerations, but may be provided upon an appropriate request to the corresponding author.

Received: 17 June 2021; Accepted: 1 November 2021;

Published online: 22 November 2021

\section{Notes}

1 https://www.youtube.com/watch?v=SRZ0rf54-OI. Accessed 19 Oct 2020.

2 https://www2.helsinki.fi/en/researchgroups/amriwa. Accessed 27 Oct 2021

3 The outbreak of the Coronavirus pandemic halted fieldwork in March 2020.

4 https://www.worldometers.info/gdp/gdp-per-capita/. Accessed 31 May 2021.

5 https://beninrevele.bj/en/sectoral-projects-and-reforms/agriculture/ and http:// www.fao.org/faolex/results/details/en/c/LEX-FAOC146068/. Accessed 08 June 2021.

6 Pastoralism (and its attendant $\mathrm{ABU}$ ) is a feature of both rural economies (Dognon et al., 2018; Samandoulougou et al., 2016), although it did not form part of this current research.

7 See also see Blanchette (2019, 2020), Buller et al. (2020), Hinchliffe et al. (2016) and Porter (2019). Blanchette (2019, p. 93) describes selective breeding as systematic and engineered forms of disablement, requiring the establishment proper biosecurity measures to ensure the animals survive the rearing processes.

8 None of the farms we visited had proper showering or handwashing facilities, and often footbath solutions were changed infrequently or left empty.
9 Buller et al. (2020, p. 7) discuss a similar diagnostic and metaphylactic intervention in the UK livestock sector.

10 https://new.e-urmapha.com/. Accessed 27 Oct 2021.

\section{References}

Al-Mustapha AI, Adetunji VO, Heikinheimo A (2020) Risk perceptions of antibiotic usage and resistance: a cross-sectional survey of poultry farmers in Kwara State, Nigeria. Antibiotics 9(7). https://doi.org/10.3390/ antibiotics 9070378

Alhaji NB, Haruna AE, Muhammad B et al. (2018) Antimicrobials usage assessments in commercial poultry and local birds in North-Central Nigeria: associated pathways and factors for resistance emergence and spread. Prev Vet Med 154:139-147. https://doi.org/10.1016/j.prevetmed.2018.04.001

Belton B, Bush SR, Little D (2018) Not just for the wealthy: rethinking farmed fish consumption in the Global South. Global Food Secur 16:85-92. https:// doi.org/10.1016/j.gfs.2017.10.005

Bianco A, Budroni M, Zara S et al. (2020) The role of microorganisms on biotransformation of brewers' spent grain. Appl Microbiol Biotechnol 104(20):8661-8678. https://doi.org/10.1007/s00253-020-10843-1

Blanchette A (2019) Infinite proliferation, or the making of the modern runt. In: Besteman C, Gusterson H (eds) Life by algorithms: how roboprocesses are remaking our world. University of Chicago Press, Chicago, London, pp. 91-106

Blanchette A (2020) Porkopolis. Duke University Press, Durham

Broom A, Kenny K, Prainsack B et al (2020) Antimicrobial resistance as a problem of values? Views from three continents. Crit Public Health https://doi.org/ $10.1080 / 09581596.2020 .1725444$

Buller H, Adam K, Bard A et al (2020) Veterinary diagnostic practice and the use of rapid tests in antimicrobial stewardship on UK livestock farms. Front Vet Sci 7. https://doi.org/10.3389/fvets.2020.569545

Butcher A (2017) Networks and practices of weather and climate in the Western Himalaya. Eur Bull Himal Res 49:5-34

Chandler CIR (2019) Current accounts of antimicrobial resistance: stabilisation, individualisation and antibiotics as infrastructure. Palgrave Commun 5. https://doi.org/10.1057/s41599-019-0263-4

Collignon P, Beggs JJ, Walsh TR et al. (2018) Anthropological and socioeconomic factors contributing to global antimicrobial resistance: a univariate and multivariable analysis. Lancet Planet Health 2(9):e398-e405. https://doi.org/ $10.1016 / \mathrm{s} 2542-5196(18) 30186-4$

Denyer Willis L, Chandler C (2019) Quick fix for care, productivity, hygiene and inequality: reframing the entrenched problem of antibiotic overuse. BMJ Glob Health 4(4). https://doi.org/10.1136/bmjgh-2019-001590

Dognon SR, Antoine-Moussiaux N, Douny C et al. (2018) The use of antibiotics in cattle in North-East Benin: pharmaceutical inventory and risk practices of cattle breeders. Trop Anim Health Prod 50(7):1683-1699. https://doi.org/ $10.1007 / \mathrm{s} 11250-018-1612-9$

FAO (2020) Improving communications for antimicrobial resistance (AMR) in Africa: How should we move forward? FSN Forum in Africa report of activity No. 16. http://www.fao.org/policy-support/tools-and-publications/resourcesdetails/en/c/1371889/. Accessed 11 Jan 2021

Gordon N, Amos B, Azore E et al. (2020) The UK Fleming Fund: developing microbiology laboratory capacity for AMR surveillance. Int J Infect Dis 101:86

GPSDD (2021) People power: using citizen-generated data to address antimicrobial resistance in Kenya. Global Partnership for Sustainable Development Data. https://www.data4sdgs.org/sites/default/files/2021-09/AMR-report-V4.pdf. Accessed 30 Sept 2021

Haraway D (1988) Situated knowledges: the science question in feminism and the privilege of partial perspective. Fem Stud 14(3):575-599

Hedman HD, Vasco KA, Zhang L (2020) A review of antimicrobial resistance in poultry farming within low-resource settings. Animals 10(8):1264. https:// doi.org/10.3390/ani10081264

Helmreich S (2009) Alien ocean: anthropological voyages in microbial seas. University of California Press, Berkley, London

Hendriksen RS, Munk P, Njage P et al (2019) Global monitoring of antimicrobial resistance based on metagenomics analyses of urban sewage. Nat Commun 10(1). https://doi.org/10.1038/s41467-019-08853-3

Hinchliffe S (2015) More than one world, more than one health: re-configuring interspecies health. Soc Sci Med 129:28-35. https://doi.org/10.1016/ j.socscimed.2014.07.007

Hinchliffe S, Bingham N, Allen J et al. (2016) Pathological lives: disease, space and biopolitics. John Wiley \& Sons, Chichester

Hinchliffe S, Butcher A, Rahman MM (2018) The AMR problem: demanding economies, biological margins, and co-producing alternative strategies. Palgrave Commun 4(1). https://doi.org/10.1057/s41599-018-0195-4

Houedjofonon EM, Ahoyo Adjovi NR, Chogou SK et al. (2020) Scale economies and total factor productivity growth on poultry egg farms in Benin: a 
stochastic frontier approach. Poult Sci 99(8):3853-3864. https://doi.org/ 10.1016/j.psj.2020.03.063

Iskandar K, Molinier L, Hallit S et al (2020) Drivers of antibiotic resistance transmission in low- and middle-income countries from a "One Health" perspective-a review. Antibiotics 9(7). https://doi.org/10.3390/antibiotics9070372

Kahn LH (2016) One health and the politics of antimicrobial resistance. JHU Press

Kakkar M, Chatterjee P, Chauhan AS et al. (2018) Antimicrobial resistance in South East Asia: time to ask the right questions. Glob Health Action 11(1):1483637. https://doi.org/10.1080/16549716.2018.1483637

Kirchhelle C (2018) Pharming animals: a global history of antibiotics in food production (1935-2017). Palgrave Commun 4(1). https://doi.org/10.1057/ s41599-018-0152-2

Kirchhelle C (2020) Pyrrhic progress: the history of antibiotics in anglo-american food production. Rutgers University Press, New Jersey, London

Kirchhelle C, Atkinson P, Broom A et al (2020) Setting the standard: multidisciplinary hallmarks for structural, equitable and tracked antibiotic policy. BMJ Glob Health 5(9). https://doi.org/10.1136/bmjgh-2020-003091

Law J (2004) And if the global were small and noncoherent? Method, complexity, and the baroque. Environ Plan D 22(1):13-26. https://doi.org/10.1068/d316t

Law J, Afdal G, Asdal K et al. (2013) Modes of syncretism: notes on noncoherence. Common Knowl 20(1):172-192. https://doi.org/10.1215/0961754x-2374817

Ledingham K, Hinchliffe S, Jackson M et al. (2019) Antibiotic resistance: using a cultural contexts of health approach to address a global health challenge. WHO Regional Office for Europe, Copenhagen

Nwokike J, Clark A, Nguyen PP (2018) Medicines quality assurance to fight antimicrobial resistance. Bull World Health Organ 96(2):135-137. https:// doi.org/10.2471/BLT.17.199562

O’Neill J (2016) Tackling drug-resistant infections globally: final report and recommendations. Rev Antimicrob Resist. https://amr-review.org/. Accessed 15 June 2021

Porter N (2019) Viral economies: bird flu experiments in Vietnam. University of Chicago Press, Chicago, London

Samandoulougou S, Ilboudo AJ, Sanon/Ouédraogo G et al. (2016) Utilisation de medicaments veterinaires en production bovine et aviaire et securite sanitaire des aliments d'origine animale au Burkina Faso. Int J Multi-Discipl Sci 4(1):50-79

Singh PK (2017) One Health approach to tackle antimicrobial resistance in South East Asia. BMJ 358:j3625. https://doi.org/10.1136/bmj.j3625

Suchiradipta B, Saravanan R (2016) Social media: shaping the future of agricultural extension and advisory services. GFRAS Interest Group on ICT4RAS discussion paper. https://doi.org/10.13140/RG.2.2.10815.56488

Thompson R (2021) Penning pigs: pig rearing practices, biosecurity measures, and outbreaks of African Swine Fever in Central Uganda. Hum Organ 80(1):17-26. https://doi.org/10.17730/1938-3525-80.1.17

Thoms U (2012) Between promise and threat. NTM Z Gesch Wiss Tech Med 20(3):181-214. https://doi.org/10.1007/s00048-012-0073-x

Tompson AC, Chandler CIR (2021) Addressing antibiotic use: insights from social science around the world. A report collated with social scientists of the Antimicrobials in Society Hub. London School of Hygiene and Tropical Medicine, London, 10.17037/PUBS.04659562

Van Boeckel TP, Brower C, Gilbert M et al. (2015) Global trends in antimicrobial use in food animals. Proc Natl Acad Sci USA 112(18):5649-5654. https:// doi.org/10.1073/pnas.1503141112

Van Boeckel TP, Glennon EE, Chen D et al. (2017) Reducing antimicrobial use in food animals. Science 357(6358):1350-1352. https://doi.org/10.1126/ science.aao1495

Van Boeckel TP, Pires J, Silvester R et al (2019) Global trends in antimicrobial resistance in animals in low- and middle-income countries. Science 365(6459). https://doi.org/10.1126/science.aaw1944

Waluszewski A, Cinti A, Perna A (2021) Antibiotics in pig meat production: restrictions as the odd case and overuse as normality? Experiences from Sweden and Italy. Humanit Soc Sci Commun 8(1). https://doi.org/10.1057/ s41599-021-00852-4

WHO (2015). Global action plan on antimicrobial resistance. World Health Organisation, Geneva

WHO (2017) WHO guidelines on use of medically important antimicrobials in food-producing animals. World Health Organisation, Geneva
World Bank (2019) Pulling together to beat superbugs knowledge and implementation gaps in addressing antimicrobial resistance. World Bank, Washington

Wynne B (2013) Rationality and ritual: participation and exclusion in nuclear decision-making. Earthscan from Routledge, Abingdon, New York

\section{Acknowledgements}

The research was supported with grants from Finland's Develop Academy Programme, jointly funded by the Academy of Finland and the Ministry of Foreign Affairs (AMRIWA Grant No. 318730); the Academy of Finland Academy Project Funding (SoSaMiRe, Grant No. 324322); and the Kone Foundation, Finland (Microbial Lives: Practices of New Human-Microbial Cultures, Grant No. 201802186). Dr Isidore Bongkoungou (Université Joseph Ki Zerbo, Burkina Faso), Dr. Victorien Dougnon (URMAPha, University of Abomey-Calavi, Benin), and Professor Jacques Dougnon (University of Abomey-Calavi, Benin) assisted with field planning and coordination of field visits, interviews, and focus groups. Dr. Evariste Bako (Polytechnic University Center of Tenkodogo, Burkina Faso), Mariette Aikpe (Laboratory of Applied Medical Anthropology, University of Abomey Calavi, Benin), and Marie Hidjo (URMPha, University of Abomey-Calavi, Benin) provided extensive field support and translation assistance. The authors thank the three agribusinesses and their staff for allowing us to stay on their premises with almost unrestricted access to their production practices and management records.

\section{Competing interests}

The authors declare no competing interests.

\section{Ethical approval}

Ethical approval for the research was received from University of Helsinki Ethical Review Board in the Humanities and Social and Behavioural Sciences (Finland); Comite Nationa d'Ethique por la Recherche en Sante (Benin); and Ministere de la Sante; Ministere de l'Enseignement Superieur, de la Recherche Scientifique et de l'Innovation; Comite dÉthique pour la Recherche en Sante (Burkina Faso). All research was conducted in accordance with the relevant guidelines and regulations for conducting qualitative research.

\section{Informed consent}

Written or verbal informed consent was obtained from all research participants prior to conducting the research activities.

\section{Additional information}

Correspondence and requests for materials should be addressed to Andrea Butcher.

Reprints and permission information is available at http://www.nature.com/reprints

Publisher's note Springer Nature remains neutral with regard to jurisdictional claims in published maps and institutional affiliations.

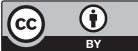

Open Access This article is licensed under a Creative Commons Attribution 4.0 International License, which permits use, sharing, adaptation, distribution and reproduction in any medium or format, as long as you give appropriate credit to the original author(s) and the source, provide a link to the Creative Commons license, and indicate if changes were made. The images or other third party material in this article are included in the article's Creative Commons license, unless indicated otherwise in a credit line to the material. If material is not included in the article's Creative Commons license and your intended use is not permitted by statutory regulation or exceeds the permitted use, you will need to obtain permission directly from the copyright holder. To view a copy of this license, visit http://creativecommons.org/ licenses/by/4.0/.

(C) The Author(s) 2021 